\title{
Hypertension guidelines : the need for robust surrogate endpoints of central blood pressure
}

\author{
Hypertension Research (2013) 36, 87; doi:10.1038/hr.2012.164; published online 18 October 2012
}

We read the guidelines ${ }^{1}$ with interest. Many practical issues have been addressed in these guidelines. However, it would have been much better if the validation involved validation against more robust surrogate endpoints of central blood pressure rather than peripheral blood pressure. ${ }^{2-4}$ These more robust endpoints could include MR-derived aortic distensibility, ${ }^{4}$ MR-derived pulse wave velocity, ${ }^{5,6}$ or central-derived blood pressure measures (such as tonometric pulse wave velocity, CAVI or the augmentation index). This validation is important because central blood pressure is the pressure that the left ventricle 'sees'. As we move down the vascular tree, the stiffness of the vessels increases; hence, the capacity to dampen the aortic pressure decreases, and the peripheral pressure is therefore several $\mathrm{mm}$ of $\mathrm{Hg}$ higher than the central blood pressure. ${ }^{7,8}$

This stiffness of the blood vessels also depends on many factors, including age, gender and BMI. When advising patients about the self-monitoring of blood pressure, a 'normal individualized range' should be recommended. However, to achieve this target monitoring would be required in the clinic for a certain period.

\section{CONFLICT OF INTEREST}

The authors declare no conflict of interest.

\section{Aitzaz Bin Sultan Rai and Saima Amin Mughal}

Clinical Research Fellow, Green Templeton College, University of Oxford, Oxford, UK

E-mail: Aitzaz.rai@gtc.ox.ac.uk

1 Imai Y, Kario K, Shimada K, Kawano Y, Hasebe N, Matsuura H, Tsuchihashi T, Ohkubo T, Kuwajima I, Miyakawa M, as members of the Japanese Society of Hypertension Committee for Guidelines for Self-monitoring of Blood Pressure at Home. The Japanese Society of Hypertension Guidelines for Self-monitoring of Blood Pressure at Home (Second Edition). Hypertens Res 2012; 35: 777-795.
2 Karamanoglu M, O'rourke MF, Avolio AP, Kelly RP. An analysis of the relationship between central aortic and peripheral upper limb pressure waves in man. European Heart Journal 1993; 14: 160-167.

3 Agabiti-Rosei E, Mancia G, O'Rourke MF, Roman MJ, Safar ME, Smulyan H, Wang J-G, Wilkinson IB, Williams B, Vlachopoulos C. Central blood pressure measurements and antihypertensive therapy. Hypertension 2007; 50: 154-160.

4 Lewandowski AJ, Lazdam M, Davis E, Kylintireas I, Diesch J, Francis J, Neubauer S, Singhal A, Lucas A, Kelly B, Leeson P. Short-term exposure to exogenous lipids in premature infants and long-term changes in aortic and cardiac function. Arterioscler, Thromb Vasc Biol 2011; 31: 2125-2135.

5 Davis EF, Newton L, Lewandowski AJ, Lazdam M, Kelly BA, Kyriakou T, Leeson P. Pre-eclampsia and offspring cardiovascular health: Mechanistic insights from experimental studies. Clin Sci 2012; 123: 53-72.

6 Lewandowski AJ, Pitcher A, Banerjee R, Leeson P. Arterial stiffness: using simple surrogate measures to make sense of a biologically complex phenomenon. Hypertens Res 2012; 35: 155-156.

7 Safar ME, Levy BI, Struijker-Boudier H. Current perspectives on arterial stiffness and pulse pressure in hypertension and cardiovascular diseases. Circulation 2003; 107: 2864-2869.

8 Zieman SJ, Melenovsky V, Kass DA. Mechanisms, pathophysiology, and therapy of arterial stiffness. Arterioscler, Thromb Vasc Biol 2005; 25: 932-943. 